\title{
BANCO CENTRAL DE BRASIL: ¿PÚBLICO O PRIVADO? REFLEXIONES SOBRE LA AMBIVALENCIA DEL BANCO CENTRAL DE BRASIL Y SOBRE EL AMPARO LEGAL DE LA EMISIÓN DE MONEDA
}

\author{
Thiago Perez Bernardes de Moraes ${ }^{1}$ \\ Universidad Argentina John F. Kennedy
}

http://dx.doi.org/10.5209/rev_NOMA.2013.v38.42918

\begin{abstract}
Resumen.- El Banco Central de Brasil es una autarquía del gobierno federal que detiene el monopolio de la emisión de moneda. En la mayoría de los países desarrollados el banco central es de propiedad privada. Pero, en Brasil y en otros países con desarrollo tardío, el banco central es público. Ocurre sin embargo, que los bancos centrales públicos operan prácticamente del mismo modo que los privados, especialmente en relación a la emisión de moneda que, por medio de artificios legales, es un monopolio privado en casi todo el mundo. Ese trabajo tiene como objetivo analizar esa dicotomía público/ privado, a partir del análisis del amparo legal de la emisión de moneda en Brasil. En este punto concluimos que hay evidencias que apuntan que el grado de independencia que el Banco Central de Brasil ha adquirido guarda relación con presiones ganadas por elites económicas (que se benefician de los títulos de deuda pública), sobre elites políticas.
\end{abstract}

Palabras clave.- Banco Central de Brasil, amparo legal, deuda pública, política monetaria

\section{Central Bank of Brazil: public or private? Reflections on the ambivalence of the Central Bank of Brazil and on the legal protection of the issuance of currency}

\begin{abstract}
The Central Bank of Brazil is a federal government agency which holds the monopoly on the issuance of currency. In most developed countries the central bank is privately owned. But, in Brazil and in other countries with delayed development the central bank is public. Occurs, however, that the public central banks operate pretty much the same way as private ones, in particular regarding the issuance of currency, through legal artifice, is a private monopoly in almost all over the world. This study aims to analyze the public-private dichotomy, from the analysis of the legal support of issuance of currency in Brazil. At this point we concluded that there is evidence to show that the degree of independence that the Central Bank of Brazil acquired guard relationship with pressures received by economic elites (who benefit from the public debt titles), on political elites.
\end{abstract}

Keywords.- Bank Central of Brazil, legal protection, public debt, monetary policy.

\section{Introducción}

Bancos Centrales son como pivote de las relaciones políticas y económicas en todas las democracias del mundo. Generalmente a ellos es conferido el monopolio en relación a la emisión de moneda y también el derecho de establecer y administrar la tasa de interés. Eso confiere al presidente del banco central, y demás autoridades de estas instituciones, un gran poder político,

\footnotetext{
${ }^{1}$ El autor es analista político y profesor de derecho y ciencias sociales. Es un investigador de la Universidad Argentina John F. Kennedy en el área de la psicología social. Thiagomoraessp@hotmail.com
} 
sobretodo lo que dice respecto a la posibilidad de ganga individual para con el mercado financiero. En el límite podríamos decir que el presidente de los bancos centrales de todo el mundo, ejercen mayor influencia sobre la vida de las personas que el presidente de la mayoría de los países. Aquí hay una ambivalencia que la ciencia política y el derecho han demostrado poco interés en responder. ¿Al final, si el banco central detiene tanto poder, porque los medios de reclutamiento de sus puestos no son hechos de manera democrática, a través de elección directa por ejemplo? Esa es una pregunta difícil de responder, y huye del escopo de este trabajo, sin embargo a través del caso brasileño obtendremos algunos insights útiles.

El caso brasileño es peculiar, pues mismo el banco central siendo público (diferentemente de los países desarrollados donde ellos de praxis son privados), el actúa como un banco privado, pues detiene el monopolio de la emisión de moneda y también el monopolio sobre el derecho de control de las políticas económicas, sobretodo lo que dice respecto del establecimiento de la tasa de interés. A medida que la política económica brasileña básicamente está dirigida principalmente a la "lucha contra la inflación", en lo cual se utiliza como principal instrumento la tasa de interés a las autoridades del Banco Central de Brasil, adquieren bastante poder de ganga ya que ellos detienen el monopolio sobre el control de la tasa de interés. Se entiende que esta, guarda no apenas relación directa con la ganancia sobre los títulos de la deuda pública, y también sobre el nivel de la emisión de moneda, que en este sentido, es controlada por los detentores de los bonos públicos.

Este trabajo esta dividido en cuatro partes y esta introducción. En la primera parte de este trabajo discutiremos en perspectiva histórica la función de los bancos centrales y el establecimiento de estas instituciones en Brasil y en el mundo. En la segunda parte de este trabajo analizaremos el amparo legal de la emisión de moneda en Brasil y el papel legal del Banco Central en ese juego y en el establecimiento de la política económica. En la tercera parte de este trabajo discutiremos sobre la política económica en Brasil proyectada por el Banco Central de Brasil, con especial atención al endeudamiento público y la ineficacia de la política monetaria. En la cuarta parte de este trabajo esbozamos algunas breves consideraciones finales.

\section{La creación de los bancos centrales}

Corazza (2001) propone una versión teórica interesante acerca del surgimiento de los bancos centrales, partiendo de dos hipótesis dicotomiítas. La primera es la de que los bancos centrales fueron creaciones arbitrarias del Estado, a favor de los intereses del Estado. La segunda es la de que fue una decisión dirigida hacía el mercado y llevada por el como un fruto natural del desarrollo del capitalismo, donde el sistema bancario a menudo tuvo que enfrentar duras crisis. La finalidad es comprender la raíz de la ambivalencia de los bancos centrales, público versus privada (Corazza, 2001, 127-36).

La experiencia histórica demuestra que los bancos centrales no surgieron de la misma manera, como seria el caso de la transformación de cámaras de compensación, no fueron solo las fuerzas de mercado que impulsan a esa metamorfosis. Las razones de la creación de bancos centrales, además, son 
frutos de la interacción entre la acción política y el mercado, de la convergencia del interés del "mercado".

La cuestión acerca de la naturaleza de la creación de los bancos centrales no puede ser resumida de acuerdo con la primera hipótesis, que fueron razones meramente políticas que llevaron a su fundación arbitraria por el Estado, ni la segunda hipótesis, que los bancos centrales son frutos de las fuerzas de mercado. Lo que se tiene entonces como razón, con más adhesión a la realidad es que los bancos centrales resultaron de la interacción entre el mercado y sus necesidades y de la respuesta del gobierno, a través de la intervención. Los bancos centrales en este sentido no fueron creados para ejercer lo que se entiende hoy como funciones de bancos centrales, pero el desempeño de estas instituciones lo llevaron a eso (Corazza, 2001, p.127-8). De cierta forma esa relación se reproduce en mayor o menor medida conforme las individualidades políticas y sociales de los diversos países. En el caso de Brasil, el camino que ha tomado los poderes del Banco Central de Brasil parece convergir con el interés de un grupo social bien distinto, que son las elites financieras.

Ser banco del gobierno, banco de emisión y guardián de reservas, aunque no sean funciones vitales de bancos centrales, fue el hito que permitió su ascensión. Sin embargo, los bancos centrales pasan a ser considerados únicos cuando comienzan a desarrollar la función de prestadores de última instancia. En la coyuntura moderna el sistema monetario se ha puesto en un trípode compuesto por el gobierno, bancos privados y por los bancos centrales. Así, los bancos centrales no pueden ser encarados como simples órganos gubernamentales, han de ser entendidos como complejos y ambivalentes, semipúblicos y semiprivados pues parte de su actuación se insiere en la estructura estatal y parte se relaciona con el crédito privado en una doble inserción, en una ambivalencia público-privada. (Corazza, 2001, 138-41).

Los primeros bancos centrales del mundo fueron el de Suecia (1688), de Inglaterra (1694), Francia (1800) y Holanda (1814), y ninguno de ellos ha asumido desde el inicio el monopolio de la emisión de moneda. En el caso de Suecia, ese monopolio solo fue implantado en 1904 (Chang, 2004, p. 166-8). En Brasil, la Constitución de 1988, establece que la emisión de moneda compite a la Unión, pero transfiere esta competencia al Banco Central de Brasil. Lo que se observa en la práctica es que la Unión no interfiere en el asunto y el Banco Central actúa como coordinador general de un monopolio de emisión de dinero.

\section{El proceso de emisión de moneda por los bancos centrales}

La moneda puede ser entendida como una reserva de valor, como un medio de pago para la circulación de mercancías y una medida de valor. A través de la moneda, todos los bienes y productos son medidos en dinero, y el acceso a ellos también se da por el dinero, desde que la sociedad en consenso acepte ese medio de pago. También a través del dinero se establecen los precios, y por fin el dinero mientras reserva de valor guarda la tónica de la posibilidad de acúmulo. La moneda aún puede, de acuerdo con el contexto social, adquirir otras funciones como la moral (cuando utilizada por la Iglesia, por la caridad), 
para fines institucionales (cuando utilizada por el Estado), o como doméstica (cuando utilizada para fines familiares) (Burigo, 2000, p4.6).

El dinero en la historia tuvo una larga trayectoria hasta ocupar el papel que hoy tiene en las relaciones políticas y sociales. El fue desde la antigüedad un instrumento de cambio, siendo utilizados diversos materiales como conchas, sal, etc. Es importante destacar que la moneda, a lo que parece, siempre tuvo como característica endémica el lastro de un poder político. La construcción y manutención de las sociedades modernas bajo la égida de un poder político pasa también por el consenso del establecimiento de una moneda única en un determinado territorio. Con la consolidación del Estado moderno el dinero ha dejado de ser apenas un medio de intercambios y se ha vuelto también en un fuerte instrumento de manutención del poder político.

El dinero en alguna medida puede ser entendido como un instrumento del Estado en el intuito de imponer la condición de deudores al pueblo, así garantizando su poder a través de medios coercitivo, en este caso, los tributos. Pero, la moneda es en si una creación del mercado, al poder político pronto le dieron la función de celar por su valor. El dinero revela una clara relación de poder, pues apenas el Estado consigue imponer el pago compulsorio de impuestos. (Metri, 2007, 2012).

Un problema grave que desafía la sociedad es el ahorro, a medida que la persona que ahorra saca dinero de circulación. La teoría neoclásica hoy predominante niega esta retirada de dinero de circulación simplemente asumiendo el presupuesto que toda cuenta de ahorro es de inmediato transformada en inversión productiva. Sin embargo, la simple observación de que el crédito es utilizado también tanto por el gobierno para pagar intereses como por las personas y empresas para la compra de bienes de consumo, de inmuebles usados, de acciones, etc., ha demostrado que este presupuesto neoclásico no tiene fundamento.

Un asunto interesante en cuanto al dinero es el uso de monedas alternativas, que surge de la escasez localizada de la moneda, lo que ha impedido y aun impide el desarrollo económico de comunidades alejadas de los grandes centros. Es posible ver a lo largo de la historia reciente de los ejemplos levantados por Búrigo (2000), que las monedas alternativas o paralelas desempeñaron un papel más relevante para la economía de las localidades donde fueron implementadas que la propia moneda oficial. Habiendo una moneda local, emitida por una autoridad reconocida por la sociedad, la demanda de los productos locales crece y, consecuentemente, aumentan la producción y el empleo en la comunidad, desde que el Banco Central competente no interfiera.

El surgimiento de monedas paralelas y alternativas en diversos países aclara una nueva cuestión: ¿Hasta qué punto la emisión de moneda debe ser restricta solo al Estado? Lo peor, en el caso de Brasil, es que la escasez de monedas en muchas localidades habría sido impuesta en la Constitución de 1988, al prohibir el Banco Central financiar directa o indirectamente el Tesoro Nacional. Así, el Banco Central no puede emitir moneda para pagar gastos del gobierno federal para promover el desarrollo económico del país. Todavía se nos queda una cuestión: ¿Si el Banco Central de Brasil emite monedas y no es para 
promover el desarrollo económico como hacen algunas comunidades periféricas, para quienes son entonces?

\subsection{El amparo legal de la emisión de moneda en Brasil - La base legal de la actuación del Banco Central de Brasil}

Hay tres casos en que el Banco Central de Brasil emite moneda. El primero es para cubrir el eventual déficit primario o fiscal del gobierno federal, el segundo es por la política cambial cuando hay un superávit en cuentas corrientes con el exterior y la tercera vía es para pago de interés de la deuda pública. En el primer y según caso, el Banco Central es pasivo, o sea, solo reacciona a favor de la decisión del gobierno federal. En la tercera situación es donde el tiene autonomía, no solo en remunerar los títulos a los capitalistas financieros, como también salvar bancos en crisis y encubrir desvíos y posibles fraudes. (Lima, 2002, p.33-4).

El Banco Central emite monedas para el pago de interés, sin embargo el hace todo eso de manera camuflada en las operaciones de mercado abierto, llamado de "open market" por los iniciados, donde entonces el compra títulos emitidos por el Tesoro Nacional, alegando estar haciendo política monetaria para controlar el volumen de dinero en circulación. Para comprar un bono del Tesoro Nacional de las manos de un portador cualquiera, el Banco Central emite dinero, inclusive la parte correspondiente al interés (Lima, 2000). Así, el Estado garantiza la remuneración de los acreedores de la deuda pública, sea por medio de la coerción imponiendo a toda sociedad el pago de los tributos, y cuando estos no bastan, hay una emisión de moneda nueva para el gozo de los acreedores.

Actualmente, la emisión de moneda siguiendo la disposición legal, es un monopolio de la Unión, vía Banco Central de Brasil (Kretzer, 2011, p.58). En la Constitución Federal de Brasil de 1946 y de 1967, la emisión de moneda que se fijó forzó un posible déficit. O sea, si el Tesoro Nacional estuviera en déficit, era posible vía decisión política hacía la emisión de moneda para cubrir tal déficit. En la Constitución de 1988, el Banco Central de Brasil aun detiene el monopolio de la emisión de moneda, por delegación de competencia de la Unión. Sin embargo, el $\S 1^{\circ}$ del art 164 marca una ruptura, al establecer que Banco Central no puede emitir moneda para el financiamiento del Tesoro Nacional. Con base en la Constitución Federal:

Art. 164. La competencia de la Unión para emitir moneda será ejercida exclusivamente por el Banco Central.

$\S 1^{\circ}$ Es vetado al Banco Central conceder, directa o indirectamente préstamos al Tesoro Nacional.

O sea, caso el gobierno Federal tenga un déficit, ese déficit no puede ser financiado con emisión de moneda nueva por el Banco Central de Brasil, pero sí con endeudamiento junto a los capitalistas financieros. Eso significa que la competencia de la Unión para emitir moneda nunca puede ser ejercida (Kretzer, 2011). El $\S 1^{\circ}$ del Art. 164 de la Constitución de 1988 ha solapado a los párrafos 1 y 2 de la Ley de creación del Banco Central de Brasil (Ley 4595 de 31.12.1964), que decía poder haber emisión de moneda para cubrir déficit del Tesoro Nacional. 
El poder del Banco Central de Brasil fue aumentado en la ley de consolidación de creación del Plan Real (Ley 9.069 de 29 de junio de 1995) al establecerse que:

Art. $6^{\circ}$ - El presidente del Banco Central de Brasil someterá al consejo Monetario Nacional, en el comienzo de cada trimestre, programación monetaria para el trimestre, que deberá incluir, como mínimo:

I - estimativas de los rangos de variación de los principales agregados monetarios compatibles con el objetivo de asegurar la estabilidad de la moneda;

II - análisis de la evolución de la economía nacional prevista para el trimestre, y justificativa de la programación monetaria.

$\S 1^{\circ}$ - Tras aprobación del Consejo Monetario Nacional, la programación monetaria será remitida a la Comisión de Asuntos Económicos del Senado Federal.

Así, todas las directrices previstas por el Banco Central de Brasil para el cumplimiento de la pretensa estabilidad de la moneda se vuelven prioridad en la agenda. En este caso, tanto el Ministerio de Hacienda cuanto a la Presidencia de la República y todo el poder político se quedan rehén de esa política de estabilización del Banco Central y no pueden ejercer otra política (Kretzer, 2011, p.38). Sin embargo, la ley establece la participación del Congreso Nacional en la aprobación o reprobación de los planos del Banco Central, pero, de manera rara, pues el final del artículo 6 de la Ley 4595, se queda cristalizada la independencia del Banco Central, cuando se establece que:

$\S 6^{\circ}$ - Caso el Congreso Nacional no apruebe la programación monetaria hasta fines del primero mes del trimestre a que se destina, se autoriza al Banco Central ejecutarla hasta su aprobación.

Ese dispositivo autoriza el Presidente del Banco Central de Brasil a actuar con plena libertad, no importando o cuan dañoso eso sea. Entra entonces la respuesta para la cuestión de para quienes el Banco Central de Brasil emite dinero, encontrada en el Art. 12 de la Ley 4595, donde se dice:

Art. 12 - El Banco Central de Brasil operará exclusivamente con instituciones públicas y privadas, vedadas operaciones bancarias de cualquier naturaleza con otras personas de derecho público o privado, excepción de lo expresamente autorizado por la ley.

El Banco Central es una autarquía del gobierno federal que ya tiene en términos legales autonomía operacional y patrimonial, solo no posee aún la letra de la ley la independencia administrativa, que seria el aislamiento máximo de sus autoridades, pues a los dirigentes no se podrían demitir. El Banco Central de Brasil tiene plena libertad para formular e implementar la política monetaria sin interferencia legal del Ministerio de Hacienda y de la Presidencia de la República. (Freitas, 2006).

Según Benayon (2005), en la práctica el Banco Central brasileño ya posee una larga independencia ya que no tiene de hacer licitaciones para endeudar el país. En este sentido el está libre para establecer altas tasas de interés, mismo que no sean eficientes en el combate a la inflación y agranden aun más la 
deuda del Gobierno Federal. El debate acerca de la independencia del Banco Central, según el profesor Castro (2005), obstruye la fluidez de un diálogo aún más necesario en la sociedad referente a la administración de la política económica que garantiza más equidad de derechos.

En las operaciones de mercado abierto para hacer política monetaria, el Banco Central hiere los principios de administración pública en las compras y ventas de bonos públicos por no ofrecer transparencia operacional y contable, y en larga medida es un vector para el desequilibrio de las cuentas públicas. Un detalle poco conocido es el de que en el mercado abierto son los capitalistas financieros y no el Banco Central, que deciden si, cuando y cuanto ellos compran y venden de bonos del Tesoro Nacional de/y para el Banco Central.

Los capitalistas financieros son atraídos a destinar sus recursos en los bonos de la deuda pública principalmente por cuenta de la liquidez ofrecida, que es de un $100 \%$, pues la venta del bono público en la Internet la hacen en segundos y con total seguridad. El bono público es igual a dinero, pero rinde interés por el tiempo que el aplicador quiera. El bono se queda todavía mejor cuando la tasa de interés que el Banco Central de Brasil determina para la deuda pública es más grande de que la tasa de interés de mercado, y que es lo que casi siempre hay ocurrido.

En otras palabras, el Banco Central de Brasil no detiene el control acerca del volumen de su emisión de moneda, pues cuantos más bonos de deuda pública son vendidos al sector privado, más grande será la emisión de moneda para remunerar con interés los particulares portadores de bonos públicos. No se trata de un arreglo meramente técnico, pero un claro instrumento que, de un lado, proporciona la escasez de moneda en la sociedad y, de otro, beneficia los capitalistas financieros.

La Unión no tiene control acerca de la deuda generada por el Banco Central de Brasil bajo el argumento de combate a la inflación. El gobierno federal puede hasta expandir el superávit primario, para eso aumentando los tributos y cortando gastos esenciales para la población. El superávit primario fue inventado y se volvió legalmente una obligación del gobierno en todos los tres niveles, con la específica finalidad de aprovechar los recursos así ahorrados para el pago de interés de la deuda pública. Sin embargo, esas medidas son apenas paliativas, pues el Banco Central hace nuevas deudas siempre que el capitalista financiero decide adquirir un bono público, independiente del gobierno federal necesitar o no del dinero así prestado. Por otra parte, como demostrado en Lima (2008, p.248-9), el superávit primario es capaz de cambiar el nivel de la deuda pública existente, pero no tiene el poder de alterar su trayectoria matemáticamente explosiva. Ese proceso explosivo acontece porque el gobierno es una institución social y no una empresa que tiende a ser lucrativa. Así, al tomar préstamos el gobierno pasa a gastar más de lo que arrecada de impuestos por culpa del interés. Y quien debe y sigue gastando más de lo que gana ve a su deuda crecer eternamente, sin límites. Por eso, como ilustra el gráfico abajo, la deuda pública siempre sigue un proceso matemáticamente explosivo hasta que una crisis sobrevenga. 


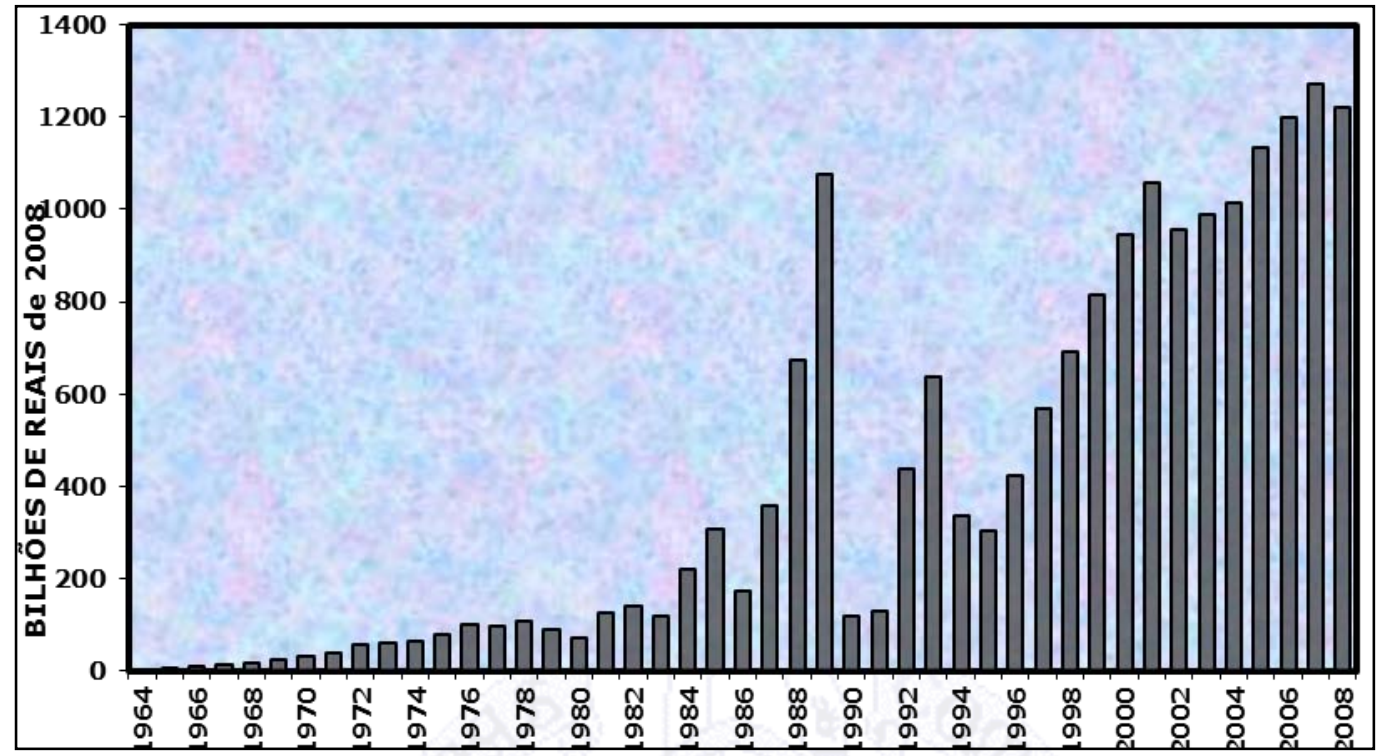

La deuda pública del gobierno federal en forma de títulos del Tesoro Nacional que están en poder del mercado financiero comenzó a crecer más fuertemente en 1980. El crecimiento explosivo de la deuda solo es interrumpido por calotes que recibieron nombres fantasía de Plan Cruzado, de 1986, Plan Collor I y II, de 1990 y 1991 y Plan Real, de 1994 (Lima, 2008, p. 258-60).

El dinero que la legislación permite que el Banco Central tome a préstamos en nombre de la Unión es el dinero que el propio Banco Central de la Unión ha emitido. Además de la confusión de orden legal, hay una paradoja muy difícil de entender, lo que nos lleva a una pregunta intrigante. ¿Porque el poder político y la sociedad aceptan ese tipo de práctica? Dicho de otra manera, esa situación se asemeja, por ejemplo a una historia hipotética donde un pequeño vinicultor que, en lugar de llevar para la cena de domingo de su familia un vino directamente de su stock, repasa este mismo vino para el supermercado y después compra el mismo vino, hecho por el mismo, aceptando pagar el precio que el supermercado establece, mismo que sea un precio muy superior a otros vinos de misma calidad. Es ilógico, pero es exactamente lo que hace el Gobierno Federal.

La Constitución impide que el Banco Central de Brasil emita dinero para financiar el Tesoro Nacional. A consecuencia, siempre que el gobierno federal tiene déficit él se endeuda junto a los capitalistas financieros que entonces prestan para el gobierno federal un dinero que fue emitido por el Banco Central.

Claro que hay una construcción teórica hecha por economistas monetarios, incesantemente pasada al sentido común por el periodismo económico, que en alguna medida puede justificar la formación de un consenso acerca de la misión del Banco Central en el control de la inflación. Sin embargo, queda claro que este "consenso" de la sociedad y del poder político en lo que se refiere al tracto de la emisión de monedas es ilógico por cuenta del proceso explosivo no solo de la deuda publica sino también del déficit público, de la rienda de interés de los pocos beneficiarios, de la emisión de dinero, del desempleo, etc. 
Por fin, la misión declarada del Banco Central de Brasil seria la de asegurar la estabilidad de la moneda, pero como el no tiene control sobre la emisión de moneda, ni sobre el nivel de endeudamiento público, ni sobre el cambio, el modus operandi adoptado por el Banco Central de practicar política monetaria a alto interés solapa cualquier posibilidad de estabilidad de moneda, luego, el Banco Central actúa en contramano de la misión que el declara en su página de Internet.

\subsection{La independencia del Banco Central de Brasil}

El análisis de los poderes del Banco Central deja claro que el ya posee una larga independencia, garantizada en un pacto político con el poder financiero (Araujo, 2005, p. 389-396). Los principales argumentos que buscan legitimar un Banco Central independiente son dos: el primero, el de facilitar la entrada de capital productivo en el país; y el otro de que la independencia propicia la confianza necesaria para gestionar la política económica. Así, habría niveles de inflación relativamente bajos y consecuentemente, tasas de interés más bajas. Ambos argumentos no se confirman en Brasil, ya que hay inflación elevada para los padrones internacionales, igual que para la tasa de interés, fijada por el Banco Central y denominada tasa Selic, y también por el tipo de capital extranjero que ha sido impulsado a entrar en Brasil, que no es productivo y sí financiero, alojado principalmente en los bonos de la deuda pública. (Araujo, 2005, p.396-7).

Otro argumento muy común por la independencia es el comportamiento posiblemente poco responsable del político preocupado con la reelección. Otro argumento dice que los políticos en época de reelección tienden a adoptar un comportamiento expansionista en relación a la política económica. Pero, como la teoría neoclásica dice que la economía ya está en su funcionamiento máximo, ese comportamiento del gobierno en realidad sería muy indeseable, pues no aumentaría el empleo y además causaría inflación.

Luego, la defensa del Banco Central independiente hace un uso deturpado de conceptos de la ciencia cuando argumenta tratarse de un órgano apolítico que debería ser aislado del poder político, que tenga reglas claras y que sobre todo esté comprometido con el combate a la inflación. Lo que ocurre es un raro discurso político por concluir, dado por el aislamiento de un grupo de tecnócratas en el alto de un Monte Sagrado, pero si fuera ese el caso, los tecnócratas no podrían tomar decisiones que afectasen la sociedad. La lógica apunta para el contrario de la arenga independentista, pareciendo que cuanto más independiente sea el Banco Central, mas sujetado estará a cooptación por medios políticos por los capitalistas financieros y por los operadores del mercado financiero que derivan sus riendas de los corretajes sobre la compra y venta de activos financieros.

Es evidente en los textos de Benayon y Rezende (2006), de Militão (2007) y de Sayad (1999), que desde la Constituyente de 1988 algunas maniobras llevaron a medidas legales de intereses de los grandes concentradores de capital, que son aquellos que compran la mayoría de los bonos de la deuda pública. Entre estas medidas están: 1) el impedimento constitucional del Banco Central emitir moneda para financiar el Tesoro Nacional; 2) la imposición al gobierno de la realización sistemática de superávit primario y la simultanea determinación de 
la prioridad de pagamento de interés de la deuda pública, ambas consolidadas en la Ley de Responsabilidad Fiscal, y 3) el Programa de Metas de Inflación, que garantiza una tasa de interés elevada. Así se garantiza a los capitalistas financieros que, durante los periodos en que ellos no encontraren mejor alternativa para aplicar su dinero, el Banco Central siempre lo tomará prestado durante el tiempo que ellos quieran y pagando tasas de interés elevadas conforme lo demuestra el grafico abajo.

\section{GRÁFICO 2 - TASA DE INTERES SELIC}

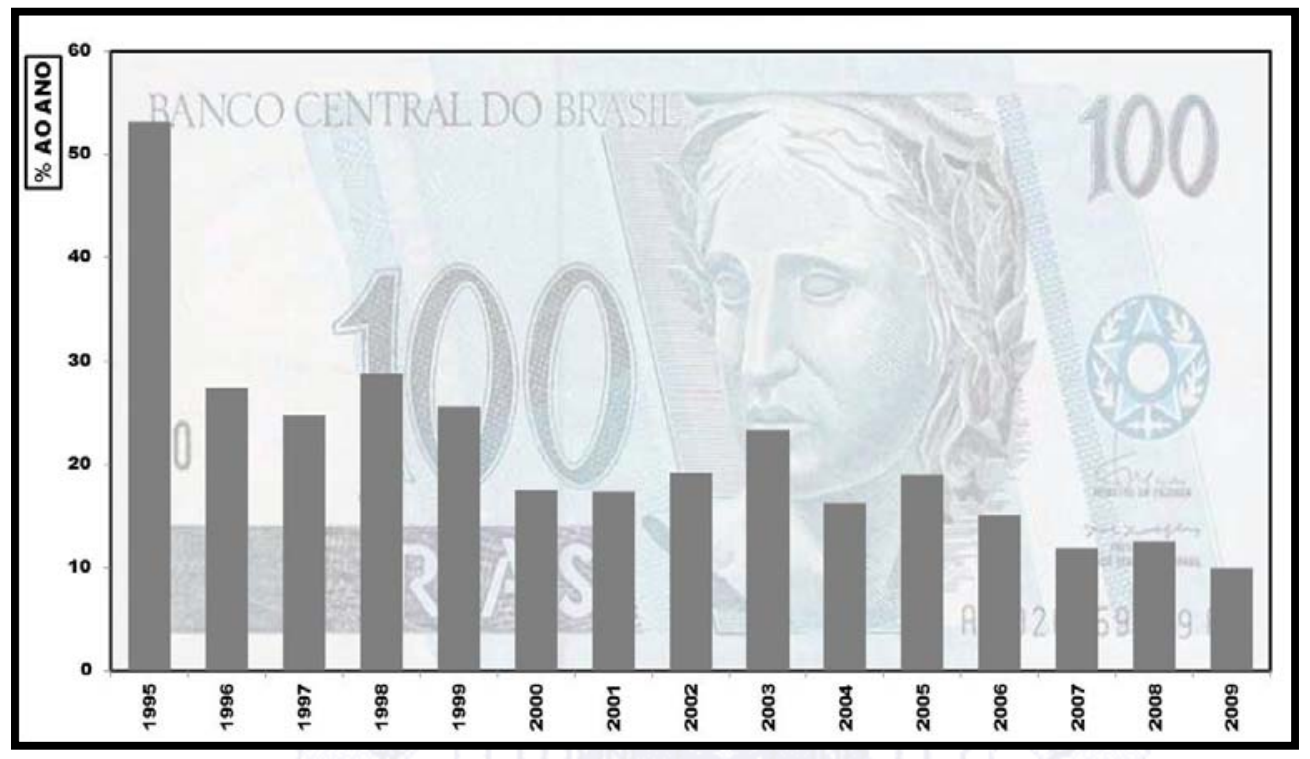

La Constitución de 1988, a pesar de buena en algunos aspectos (como la coerción al monopolio de los medios de comunicación), es bastante tolerante con el poder económico y necesita ser revisada (Nusdeo et al 2009, p 51-2). Los dirigentes de los bancos centrales dada la importancia de esta institución, ejercen más influencias en la vida de las personas que la de cualquier otro político democráticamente elegido. Sin embargo, en ningún lugar del mundo esos dirigentes son escogidos por el pueblo directamente. Hay así una institución poderosa que está totalmente fuera del control democrático (Cooper, 2008, Prado, 2011).

Todo el sitio del Banco Central de Brasil está también disponible en inglés, puesto que tiene la función de administrar todo el flujo financiero del país con el exterior. Pero, un ejemplo caricato de la subordinación del Banco Central de Brasil al poder financiero internacional es el hecho de que muchos de los textos para discusión acerca de la política económica son publicados apenas en inglés. Parece entonces que, así actuando, él pretende excluir del debate sobre sus acciones todos los brasileros que no hagan parte del selecto circulo de favorecidos que pueden tener contacto con el exterior. 


\section{3 ¿Fraude en la constitución de 1988?}

La investigación de Benayon y Rezende (2006, p.18) sobre algunos eventos relacionados a la constituyente de 1988 da soporte a la sospecha de que hubo una inclusión de dispositivos en la constitución de manera visiblemente ilegal. Los dispositivos no respetaron las tres etapas de tramitación de la constituyente y no pasaron por el plenario, lo que segundo los autores caracterizase como estelionato. Los autores apuntan que los responsables por la inclusión de esos dispositivos fueron los constituyentes Nelson Jobim y Gastone Righi. Los dispositivos en cuestión son los párrafos "a", "b" y "c" del artículo 172. Según los autores:

Esa adición al Texto Mayor ha creado de manera ilegal e ilegitima, excepciones a la norma del inciso II del actual art 166 que contemplan, además del servicio de la deuda (párrafo b), también las expensas con el personal (párrafo a) y las transferencias constitucionales a Estados y Municipios (parráfo c). Sin embargo, al contrario del servicio de la deuda esos dos tipos de gastos no son depresivos para la economía. Al revés, se destinan para actividades indispensables al funcionamiento de los gobiernos federal y locales (Benayon, Rezende, 2006, p. 14)

Los autores levantan diversas materias que fueron publicadas en la prensa con Nelson Jobim recusándose a aclarar cuáles fueron los dispositivos que entraron en la constitución de manera dudosa, pero también asumiendo la participación en actos de esa naturaleza (Benayon, Rezende, 2006, p 11-22). En una entrevista, Gastone Righi asume que de hecho hubo tal inclusión, sin embargo el atribuye que la iniciativa partió de Nelson Jobim. Este por su vez cuando procurado por las acusaciones contenidas en el paper académico de Benayon y Rezende, en vez de defenderse, ha preferido no pronunciarse sobre la encuesta. La narrativa de Benayon y Resende (2006) lleva a creer que la adición ilegal de los párrafos ha sido hecha de manera furtiva. Sin embargo, una hipótesis interesante para futuros estudios y que no es llevada en cuenta en la investigación de los autores, es que los otros parlamentares pueden haber sido sobornados, lo que volvería esa adición un poco mas consensual y facilitaría el proceso.

Como si fuera poco, a lo que parece el Banco Central realiza constantes encuentros "secretos" con el mercado financiero. Según una materia de la revista Carta Capital, trimestralmente directores del Banco Central de Brasil realizan encuentros con el mercado financiero. De esas reuniones participan apenas selectos representantes de grupos financieros y el contenido no es divulgado al público o a otras autoridades políticas. Esos encuentros no están siquiera en la agenda, o sea, no existen de manera formal. Tampoco se producen registros de esos encuentros y ningún tipo de material que pueda aclarar lo que se está discutiendo (Lirio, Pinheiro, 2007, p.1).

Según el Banco Central, esos encuentros no son divulgados pues supuestamente generarían especulaciones indeseables en el mercado financiero. O sea, no hay transparencia en este proceso, que los deja totalmente fuera del control democrático. La información es que de este encuentro salen datos concretos para que el Banco Central produzca los informes trimestrales acerca de la inflación. Sin embargo, el Banco Central ya posee una larga comunicación con el mercado que está hecha a través de la 
Gerencia Ejecutiva de Relaciones con Inversores (Gerin), donde se compila semanalmente informaciones advenidas de economistas de bancos acerca de los más diversos precios de la economía. Con esos encuentros secretos queda indubitable que la transparencia del Banco Central está en juego y hasta aquellos que plantean por un Banco Central mas "independiente" concuerdan que es necesaria una completa abertura y clareza de sus procedimientos para la sociedad y para el mercado (Lirio, Pinheiro, 2007, P.24).

Es arriesgado afirmar algo referente a los encuentros secretos, pues como su contenido no es divulgado y es complejo obtener la lista de sus participantes, queda fácil juzgar lo que vienen haciendo. Sin embargo, como el propio Banco Central afirma, de estas reuniones salen datos para la composición de los informes sobre la inflación. En ese sentido hay una hipótesis que necesita de futuros estudios para ser corroborada o no, pero, en todo caso debe ser llevada en cuenta, visando maximizar los principios de transparencia del Banco Central. Ya que estos encuentros ocurren a puertas cerradas y no hay posibilidad de control por ninguno de los tres poderes (ejecutivo, legislativo y judicial) siquiera por la sociedad civil, nada impide que ahí estén discutiendo intereses privados. Por ejemplo, se podría estar sobrestimando brutalmente el valor de la inflación visando justificar tasas mayores de interés Selic. Lo que interesa a los representantes del mercado financiero que participan de esos encuentros indubitablemente son las tasas de interés elevadas para garantizar sus ganancias.

\section{La política monetaria, una ficción - Financiamiento del déficit público}

Es el poder político que da fuerza a la moneda, pues ella es una ficción contable sujeta a la fuerza del poder político. Un ejemplo de este poder es el Dólar, que solo es acepto como reserva universal, como principal unidad de cambio de la tierra, por cuenta del considerable poder político y militar que disfrutan los Estados Unidos. Así, si cualquiera de los dos poderes, o ambos, son abalados, el valor del dólar estará en riesgo (Araujo, 1988, P.34-5).

Lo que predomina en la academia de los economistas y en el mundo real es un conjunto de reglas y presupuestos no científicamente comprobados y denominados de "monetarismo", adoptados por los monetaristas en la construcción de la teoría monetaria y en la aplicación práctica de la política monetaria con el supuesto objetivo de asegurar la estabilidad del valor de la moneda. El principio básico adoptado por los monetaristas es el de que la economía tiende a estar siempre en pleno empleo, significando que la producción nacional está en su nivel máximo. Así, según los mismos, si el gobierno emite dinero para expandir sus compras de bienes y servicios de la comunidad, solo irá acontecer un aumento de precios. Mismo que el gobierno pare de emitir moneda tras una compra, los monetaristas dicen hiperinflación. Este proceso concluyen ellos, causa muchos efectos negativos sobre la economía y la sociedad, como la caída del investimento de las empresas y el desempleo, y debe ser evitado a cualquier modo.

Por eso, en la cosecha monetarista se predice que la solución ideal para cualquier déficit del gobierno es el financiamiento por los capitalistas financieros, entre ellos los banqueros nacionales e internacionales. Así, a pesar 
del Banco Central de Brasil ser una autarquía del gobierno federal que tiene competencia para emitir dinero, se quedó establecido que el gobierno federal debe endeudarse y pagar interés, aunque el déficit esté asociado al gasto con interés de la deuda ya existente.

\subsection{Programa de metas para la inflación}

Por otra parte, el Banco Central ha extendido su preocupación con la inflación, yendo de "control" para "combate". O sea, no importa si hay o no déficit público, es misión del banco central combatir la inflación. Si fuera posible reducir precios sin reducir empleos y sueldos sería muy bueno, pero eso no existe. Los precios suben y deben subir cuando las personas ganan más porque teniendo más rienda las personas quieren comprar cosas más caras que antes no podían comprar. El paradigma monetarista ha llevado a Brasil a tomar un posicionamiento único frente a la administración de la política económica, donde primero se afirma que el único problema es la inflación, y después se recomienda que la política monetaria sea la única solución a combatir este "mal".

Así, surge el programa de metas de la inflación ${ }^{2}$, que utiliza tasas elevadas de interés en la tentativa de desacelerar el consumo. El programa es basado en un modelo matemático monetarista no sometido al test de la vida real. Además, este modelo no puede ser científicamente testeado pues es ilógicamente inconsistente, asumiendo que la deuda hecha por el gobierno no paga interés y que el desempleo observado en un determinado momento en el tiempo es necesario para reducir la tasa de variación de los precios en todos los periodos de tiempos que han de venir (Lima, 2008, p.211).

La política monetaria de metas para la inflación básicamente se define en dos momentos. En el primero se establece un objetivo, una cierta meta para la inflación y posteriormente alinease la tasa de interés Selic para supuestamente alcanzar aquella meta. El Banco Central utiliza esta tasa Selic para realizar todas sus operaciones de compra y venta de títulos del Tesoro Nacional en el mercado abierto con el objetivo, dice él, de controlar la inflación. En la práctica, todavía, lo que pasa cuando el Banco Central anuncia la tasa Selic es que él compromete al gobierno a vender títulos públicos, o sea, tomar prestado todo el dinero que el mercado financiero estuviera dispuesto a prestarlo, que entonces se obliga a devolverlo acrecido del valor de los respectivos interés a la tasa Selic (Lima, 2008, p.221-2). Se trata entonces de un fondo de aplicación financiera y no de control de stock de dinero, que podría ser llamado Fondo Selic. Es muy dudoso que se logre efectuar el control de la inflación emitiendo más moneda. Además, esa práctica va en contra del principio monetarista de que la emisión de moneda es sinónimo de inflación.

El proceso por el cual el COPOM (Comité de Política Monetaria del Banco Central de Brasil) establece las tasas de interés, que tienen consecuencias

\footnotetext{
${ }^{2}$ A partir de los años 1990 se ha tornado cada vez más común en los países desarrollados y en desarrollo la adopción del programa de metas de la inflación. Eso significa que eses países hoy están desproveídos de importantes instrumentos que podrían llevar al aumento de la demanda agregada y consecuentemente del empleo. (Freitas, 2006, p.204)
} 
visibles en toda la sociedad, sufre influencia de líderes de la economía y del gobierno, pero apenas por medio de manifestaciones de desagrado en la prensa. La "reunión" del COPOM es cerrada y el único grupo social consultado sistemáticamente es el de los componentes del mercado financiero. Los "técnicos" del mercado financiero pueden irse al Monte Sagrado, pero los "políticos" no. Ese camino de agrado a los capitalistas financieros lleva a una recesión inducida y sacrifica la economía de mercado y a los propios capitalistas financieros

Mismo en la hipótesis de que tales metas de la inflación sean bien sucedidas, o sea, que se logre limitarla a un nivel previamente establecido, el país y la economía de mercado no agregan ningún beneficio con eso (Araujo, 2005, p. 464). En ese sentido, es válido cuestionar: ¿Para que el gobierno demanda un esfuerzo tan grande para atingir una finalidad de dudosa serventía?

Si el objetivo de los paradigmas impuestos por la responsabilidad fiscal es el ajuste de las cuentas y una busca de equilibrio de las cuentas, la política monetaria anula cualquier efecto propuesto. O sea, si de un lado hay una campaña para minimizarse los gastos públicos a través de ajustes fiscales, por otro lado la política monetaria impone una deuda inmensurable, obstaculizando cualquier tentativa de equilibrio de las cuentas. Todo presupuesto público tornase dependiente del interés de la deuda pública, el desequilibrio tornase regla en contra cualquier posibilidad de equilibrio de las cuentas y desciende las posibilidades de gastos públicos productivos (Gonçalves, 1999, 2002,2005).

Como la economía es toda interconectada, la política monetaria de metas para la inflación causa tres problemas económicos inmediatos con consecuencias muy serias para la sociedad: en primero lugar, se implanta la regla legal del superávit primario, que significa sacar dinero de quien gana poco y gasta comprando productos nacionales, así, mas desempleo y menos demanda de productos industrializados brasileros, en segundo lugar, el alto interés y la globalización traen para Brasil mucho dólar para ser aplicado en bonos públicos. Como siempre sucede, cuando aumenta la oferta, cae el precio y así el dólar baja y Brasil pasa a importar más y exportar menos productos industrializados, pero lo peor es el tercer problema, pues la deuda hecha por el Banco Central en nombre del gobierno y del pueblo sigue un ritmo explosivo en dirección al infinito, desestabilizando toda la economía y la sociedad. Mientras eso, el trabajador y el empresario ganan cada vez menos y muchos de ellos nada.

En realidad, no hay indicios que apunten que los trabajadores, los industriales y los comerciantes perjudicados por cuenta de esta política económica tengan ejercida una presión significativa en el poder político para la obtención de una política económica que de hecho garantizara la manutención y el crecimiento de la demanda agregada. Parece entonces que, los sectores de la industria no emprendieron esfuerzo en este sentido por cuenta de tener riquezas financiadas con rendimiento emparejado a la tasa Selic (Pochmann et al, 2009, p.59-1). Según Pochmann, el desafío para Brasil está en formar una convergencia política en provecho del desarrollo. Solamente en este escenario, las 20 mil familias que hoy concentran el grueso de los bonos de la deuda pública tendrían incentivos para migrar ese dinero del campo improductivo para la producción generando así más empleo (Pochmann, 1999, 2001, 2002). 
La política monetaria causa concentración de rienda por tres caminos, uno de ellos es esta concentración de los bonos públicos en la mano de pocos, lo que significa que son pocos los que reciben la rienda de interés públicos, el otro es el del superávit primario, que causa caída de los sueldos y aumento del desempleo y del subempleo, el ultimo es el de la entrada de dólares que acelera la caída de sueldos y empleo. La política monetaria no apenas enriquece a algunos pero también empobrece a muchos. Sin embargo, aparentemente la concentración de rienda tiene pocas chances de causar rebeliones populares en países como Brasil, donde desempleo y subempleo siempre fueron fenómenos crónicos. Además de todo, estos conflictos tienden a ser tomados por líderes carismáticos populistas con baja propensión a la democracia.

Por fin, pero sin agotar la lista de efectos negativos de la política monetaria, es necesario entender cómo se insiere el capitalista extranjero en este contexto. Ese movimiento monetarista ha creado una rigidez cuanto a la capacidad de exportación brasilera, en un escenario donde a lo que parece Brasil se consolida como un exportador de commodities e importador, financiado con capitales extranjeros, de productos industrializados que tienen mayor valor agregado y que garantizan empleo allá fuera. La política de financiación puede desencadenar un proceso de desnacionalización de la economía casi inexorable, lo que pone el país en una condición desfavorable en el escenario internacional, pues impone luego de antemano una balanza comercial desfavorable y aun se aumenta de forma significativa el déficit de democratización de los medios de producción que pasan a ser controlados por grupos cada vez más reducidos, y en algunos casos, no son siquiera residentes del país. (Gonçalves, 1999, p.14-7, 2005; Benayon, 2011).

En consecuencia de esta política monetaria del gobierno brasilero, la deuda externa crece despacio y siempre, siguiendo un proceso explosivo, de acuerdo con la demostración matemática en Lima (2008, p. 326-9). Ampliase así también la remesa de moneda extranjera para el pago de interés, obtenida, por ejemplo, con la exportación de nuestras riquezas minerales, y aumenta la subordinación del país a los intereses externos. La política de alto interés acentúa el papel internacional de Brasil como agente pasivo en la globalización (Gonçalves, 2002, P.131-62).

\section{Consideraciones finales}

La falta de abertura democrática por parte del Banco Central de Brasil ha favorecido algunos pocos, sobre todo las familias citadas por Pochmann como detentoras de los bonos públicos, por rebeldía de la grande masa de la sociedad que se queda excluida de manera directa de ese debate. En tiempos de crisis económica de nivel mundial, es necesario repensar el papel de las instituciones de fiducia económica y también el grado de abertura y participación.

En el caso brasilero como ilustrado, la política económica adoptada, además de no ser eficiente para el fin que se propone (combatir la inflación) promueve un endeudamiento compulsivo del gobierno y también una transferencia de dinero de la sociedad para los detentores de los bonos públicos. Es evidente que esa política pueda por un lado beneficiar los detentores de los bonos, pero por otro 
lado promueve el desempleo ya que, la mayor parte de los productores que generan empleo se sienten desestimulados a practicar exportación por cuenta del cambio supervalorado que nos desfavorece, de la misma forma él no se siente estimulado en participar de la competencia local, pues por cuenta del cambio, los productos extranjeros llegan a mejor costo. Todo eso, más la garantía de los bonos, lleva a una gran parte de los industriales a financiar sus riquezas, disminuyendo los empleos en el mundo real.

Necesariamente, una mayor distribución de riqueza en el país, una ampliación en el numero de vagas de trabajo, una reducción consistente de la deuda pública, debe pasar por cambios constitucionales en lo que dice respecto al aislamiento burocrático de las autoridades del Banco Central de Brasil y también en lo que dice respecto al amparo legal de la emisión de moneda. Más allá de garantizar las ganancias de los detentores de los bonos públicos, el gobierno debe concebir también las condiciones mínimas de equidad y justicia entre los brasileros.

\section{Referencias}

Araújo, A. (1998). A escola do Rio: fundamentos políticos da nova economía brasileira (Vol. 35). Editora Alfa Omega.

Araújo, A. (2005). Moeda \& prosperidade: o impasse do crescimento na política de establização. Topbooks.

Benayon, A., (2005). Globalização versus desenvolvimento. Escrituras Editora.

Benayon, A; Rezende, P. (2006). Anatomia de uma fraude à Constituição. <http://www.cic.unb.br/docentes/pedro/trabs/fraudeac_files/fraudeac.pdf>

Búrigo, F. L. (2001). Moeda social e a circulação das riquezas na economia solidária. Florianópolis, SC, fev.

Castro, M. F. (2005). Direitos Sociais, Econômicos e Culturais: uma abordagem pós-neo-clássica.

Chang, H. J. (2004). Kicking away the ladder. London: Anthem Press.

Cooper, G. (2008). The Origins of Financial Crises: Central Banks, Credit Bubbles, and the Efficient Market Fallacy. Hampshire: Harriman House.

Corazza, G. (2001). Central Banks and Their Public-private Nature. Nova Economia, 11(1).

Freitas, M.(2006). Banco Central Independente e coordenação das políticas macroeconômicas: lições para o Brasil. 2006. Economia e Sociedade, Campinas, v. 15, n. 2 (27), p. 269-293, ago.

Gonçalves, R. (1999). Globalização e desnacionalização. Paz e Terra.

Gonçalves, R. (2000). Centralização do capital em escala global e desnacionalização da economia brasileira. $O$ Brasil e os desafios da globalização. Rio de Janeiro: Relume Dumará.

Gonçalves, R. (2002). Vagão descarrilhado: o Brasil eo futuro da economia global. Ed. Record. 
Gonçalves, R. (2005). A Macroeconomia de Lula. A Sociedade Civil e o Monitoramento das Instituições Financeiras Multilaterais. Brasília: Rede Brasil, 9-40.

Jetin, B. (2009). Le développement économique de la Thaïlande est-il socialement soutenable?. In 3ème journées du Développement du GRES.'Les Suds confrontés au développement soutenable'. Université de MontesquieuBordeaux IV.

Kretzer, E (2011). Amparo Legal da Emissão de Moeda pelo Banco Central do Brasil. Monografia (Graduação em Direito) - Faculdade Internacional de Curitiba - Facinter, Curitiba.

Krippner, G. R. (2010). The political economy of financial exuberance.Research in the Sociology of Organizations, 30, 141-173.

Lima, G. (2000). A recessão econômica pode ser um instrumento da política monetária. Revista da FAE, Curitiba, 3(2), 31-43.

Lima, G. (2008). Economia, dinheiro e poder político. Editora Ibpex.

Lirio, S.; Pinheiro, M. (2007). A República Distante. Carta Capital, n. 437, mar..

Metri, M. (2007). Poder Moeda e Riqueza na Europa Medieval. PhD. UFRJ.

Metri, M. (2012). Acumulação de poder, sistemas e territórios monetários: uma análise teórica sobre a natureza da moeda e sua relação com a autoridade central. Ensaios FEE, 33(2).

Militão, E. (2002). Segredo 2007. <http://congressoemfoco.uol.com.br/Noticia.aspx?id=16665>

Nusdeo, F., Salomâo Filho, C., Ferraz JR. (2006). Poder Economico. Editora Manole Ltda.

Pochmann, M. (1999). O trabalho sob fogo cruzado: exclusão, desemprego e precarização no final do século. Contexto.

Pochmann, M. (2001). A década dos mitos. Editora Contexto.

Pochmann, M. (2002). O emprego na globalização: a nova divisão internacional do trabalho e os caminhos que o Brasil escolheu. Boitempo Editorial.

Pochmann, M., Amorim, R. L., Guerra, A., \& Aldrin, R. (2009). Proprietários: concentração e continuidade; Owners: concentration and continuity. Atlas da nova estratificação social no Brasil, 3.

Prado, M. (2001) . A arte de comunicação da moeda. Revista Valor Econômico, São Paulo, 20 abr.

Sayad, J. (1999). O vermelho eo negro. Revista da Sociedade Brasileira de Economia Politica, (4). 